\title{
Different outcomes of managing severe intruded immature permanent incisors: A report of two cases
}

\section{Zróżnicowane wyniki leczenia ciężkiej intruzji stałych zębów siecznych z niezakończonym rozwojem korzeni - opis dwóch przypadków}

\author{
Grażyna Marczuk-Kolada ${ }^{1, A-F}$, Elżbieta Łuczaj-Cepowicz ${ }^{1, A-E}$, Małgorzata Pawińska ${ }^{2, C, D}$ \\ ${ }^{1}$ Department of Pedodontics, Medical University of Bialystok, Białystok, Poland \\ ${ }^{2}$ Department of Integrated Dentistry, Medical University of Bialystok, Białystok, Poland \\ A - research concept and design; $\mathrm{B}$ - collection and/or assembly of data; $\mathrm{C}$ - data analysis and interpretation; \\ $D$ - writing the article; $E$ - critical revision of the article; $F$ - final approval of the article
}

Address for correspondence

Grażna Marczuk-Kolada

E-mail: grazyna.kolada@umb.edu.pl

Funding sources

None declared

Conflict of interest

None declared

Received on July 27, 2017

Reviewed on September 20, 2017

Accepted on 0ctober 16, 2017

\begin{abstract}
Intrusion is a very severe injury involving damage to the periodontal ligament, cementum, alveolar bone, and neurovascular pulp supply. Current management strategies include passive repositioning by waiting for the tooth to regain its preinjury position, and active repositioning, i.e., immediate surgical repositioning or repositioning with traction.

This report describes the interdisciplinary management of complete intrusions of the maxillary right central incisors with an immature open apex in 2 different patients of a similar age but with different outcomes. The most likely causes of these differences were: ankylosis; inflammatory root resorption; and the systemic condition of the $2^{\text {nd }}$ patient. A number of preinjury and injury factors have a significant influence on the healing outcome. According to this report, prognosis after intrusive luxation appears to depend not only on the severity of the trauma, stage of root development and treatment method, but also probably on the patient's systemic condition. Therefore, the patient's current complex medical history should be taken into consideration as a factor significantly affecting the healing outcome and long-term prognosis.
\end{abstract}

Key words: corticotomy, intrusive luxation, permanent teeth, Wolfram syndrome

Słowa kluczowe: kortykotomia, zwichnięcie intruzyjne, zęby stałe, zespółWolframa

D0I

$10.17219 / \mathrm{dmp} / 78663$

Copyright

() 2017 by Wroclaw Medical University

and Polish Dental Society

This is an article distributed under the terms of the

Creative Commons Attribution Non-Commercial License

(http://creativecommons.org/licenses/by-nc-nd/4.0/) 
Intrusive luxations are characterized by tooth displacement into the alveolar bone. This injury is caused by an axially directed impact compressing the periodontal ligament with an accompanying fracture of the alveolar socket. It is a very severe injury involving damage to the periodontal ligament, cementum, alveolar bone, and neurovascular pulp supply; thereby it can compromise the vitality and ultimately affect tooth longevity. Intrusion frequency is relatively low and comprises $0.3-1.9 \%$ of all traumatic injuries to permanent dentition, but this type of trauma presents unique challenges to the clinician., ${ }^{1,2}$

Treatment decisions should take into consideration the clinical and radiographic signs and symptoms, such as occlusal misalignment, bleeding, and high-pitched metallic sound without sensitivity to percussion. Radiographic findings are useful in displaying partially or totally obliterated periodontal ligament spaces and differences in the position of the cemento-enamel junction relative to the bony crest between the traumatized tooth and its intact homolog. ${ }^{3-5}$

Intrusive luxation in permanent teeth has been associated with severe complications, such as pulp necrosis, pulp canal obliteration, inflammatory root resorption, dento-alveolar ankylosis, loss of marginal bone support, arrest of root development, and gingival retraction. ${ }^{2}$

The treatment strategy should be focused on eliminating, or at least reducing, post injury sequelae. ${ }^{3}$ The contemporary state of knowledge concerning treatment options is mainly based on clinical case outcomes. There is no agreement in the literature regarding ideal treatment for permanent tooth intrusion after injury. Depending on the stage of development and severity of injury, waiting for spontaneous re-eruption and surgical or orthodontic repositioning are recommended.,3,6

This report discusses the interdisciplinary management of severe traumatic intrusion of the maxillary central incisors in 2 different patients of a similar age but with different outcomes.

Fig. 1. Initial periapical radiograph revealing intrusion of tooth 11 and fracture of tooth 21

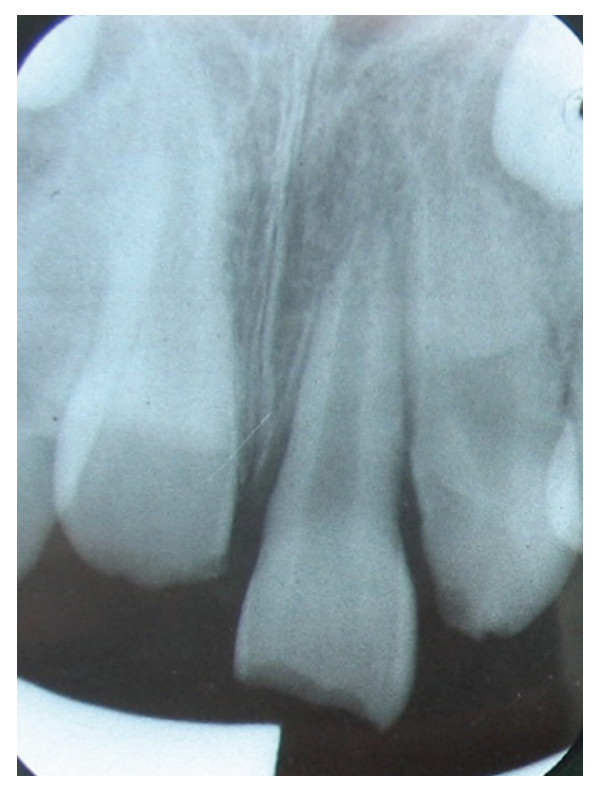
canal of tooth 11

\section{Case reports}

\section{Case 1}

A 7.5-year-old boy presented to the Pediatric Dentistry Clinic of the Faculty of Dentistry, Medical University of Bialystok, Poland, 1 day after he had fallen at the swimming pool. His past medical history, neurological and extraoral examinations were unremarkable.

Intraoral examination revealed a submucosal hematoma in the area of the maxillary labial frenulum, an uncomplicated crown fracture with dentin involvement coupled with subluxation of the maxillary left central incisor, and a small incisal fracture of the maxillary left lateral incisor. The upper right central incisor had been axially intruded (> $7 \mathrm{~mm}$, complete intrusion) as a result of the impact. In the clinical tests, both left incisors (21 and 22) did not respond to vitality tests and were not tender to percussion.

Radiographic examination confirmed a clinical diagnosis of complete intrusion of the maxillary right central incisor with an immature open apex and obliteration of the periodontal ligament space and lamina dura in relation to the intruded tooth (Fig. 1). Prior to the beginning of treatment, parental informed consent was obtained. Additionally, antibiotic therapy was prescribed for 7 days, with Augmentin ${ }^{\circledR}$ (375 mg 3 times per day), and a 14-day course of $0.12 \%$ chlorhexidine gluconate mouth rinse.

After 4 weeks, spontaneous re-eruption of the maxillary right central incisor could be identified $(5.5 \mathrm{~mm})$. The patient was referred to the orthodontist for orthodontic repositioning by extrusion. At 9 months after the trauma, clinical and radiographic examinations revealed further progress of extrusion for the upper right central incisor amounting to $9 \mathrm{~mm}$ and complete root development with closure of the apical foramen and apposition of the root dentin. Due to pulp vitality loss, endodontic therapy of

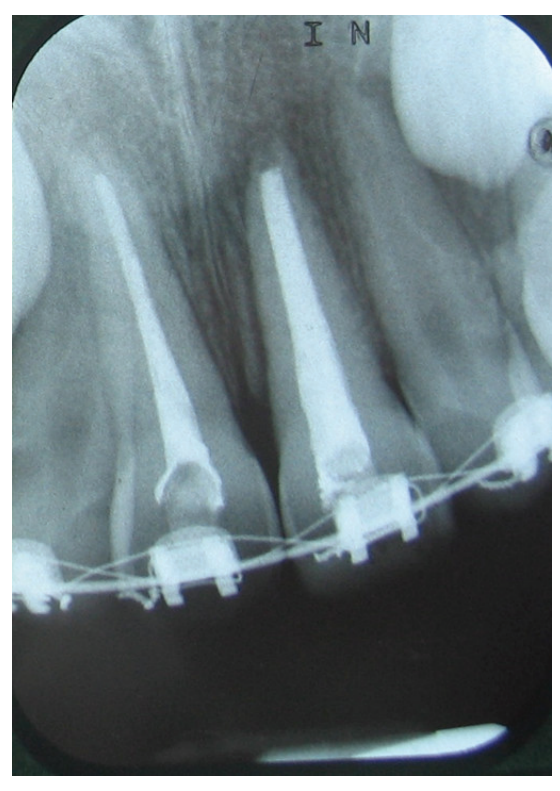

Fig. 2. Periapical radiograph after filling the root

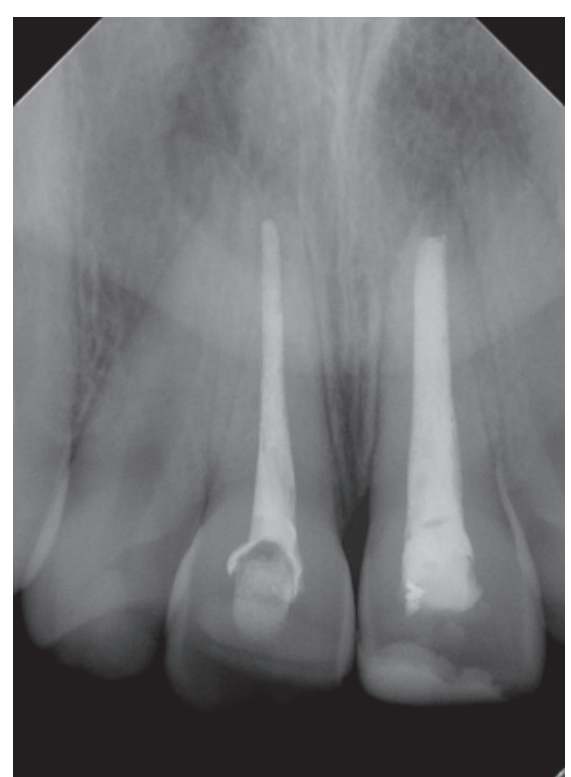

Fig. 3. Periapical radiograph 4.5 years after trauma showing successful treatment of tooth 11 
the intruded tooth was initiated. Finally, the root canal was filled with gutta-percha and epoxy resin-based sealer (Fig. 2). The tooth was restored with a light-cured resin composite and followed-up for 4.5 years. Eighteen months after the trauma, complete eruption under traction of the intruded tooth was achieved and orthodontic appliances were debonded. The tooth was clinically asymptomatic, with healthy surrounding periodontal tissue and no loss of marginal bone support. Radiographically, there was no evidence of root resorption or periapical lesions. The patient underwent a 4.5-year follow-up and showed no clinical or radiographic signs or symptoms (Fig. 3).

\section{Case 2}

A 7-year-old boy presented to the Pediatric Dentistry Clinic of the Faculty of Dentistry, Medical University of Bialystok, Poland, 2 days after he had fallen while riding his bicycle.

The neurological examination was unremarkable. Medical history revealed type 1 diabetes with good glycemic control.

Extraoral examination showed an abrasive injury to the chin and lower lip. The facial bones and TMJ were within normal limits. The right submental and submandibular lymph nodes were palpable, swollen and tender on palpation. Intraoral examination revealed a laceration and hematoma in the front central part of the maxillary alveolar mucosa.

The upper right central incisor appeared to be completely axially intruded as a result of the impact. No alterations were observed in the hard tissues of the maxillary left incisors $(21,22)$ and the maxillary right lateral incisor (12), but they did not respond to the cold test. Radiographic examination confirmed the clinical diagnosis of complete intrusion of the upper right central incisor and obliteration of the periodontal ligament space and lamina dura in relation to the intruded tooth (Fig. 4). Prior to the beginning of treatment, parental informed consent was obtained.
The patient received a 7-day course of Augmentin (375 mg 3 times per day) and a 14-day course of $0.12 \%$ chlorhexidine gluconate mouth rinse. He was instructed to maintain meticulous oral hygiene by brushing with a soft brush and prescribed a soft diet for 14 days. No re-eruption of the intruded tooth was observed. The appointments scheduled for 2,3 , and 4 weeks later demonstrated spontaneous re-eruption of the upper right central incisor by 1.5, 2.5 and $3.5 \mathrm{~mm}$ at each follow-up, respectively. After a further 4 weeks, clinical examination showed no improvement in re-eruption and the patient was referred for orthodontic repositioning by extrusion. After 6 months, as no progression in orthodontic extrusion was observed, clinical follow-up examination showed tooth immobility and infraposition, whereas an X-ray image showed the absence of the periodontal crevice around the root apex, which suggested replacement resorption (Fig. 5). A corticotomy procedure of the compact bone lamella of the maxillary alveolar process was performed around the intruded tooth, including intraoperative tooth luxation. Despite the decortication, orthodontic extrusion was proceeding slowly $-4 \mathrm{~mm}$ at 12 months following the trauma, and at 18 months $5 \mathrm{~mm}$. During this period, the patient's general health status changed. Besides type 1 diabetes, the boy developed signs of optic atrophy and underwent diagnostic procedures with the suspicion of Wolfram syndrome. Wolfram syndrome (WS) is defined with the term Wolfram DIDMOAD syndrome (diabetes insipidus, diabetes mellitus, optic atrophy, deafness). Wolfram patients demonstrate non-inflammatory atrophic changes in the brain and pancreatic islets resulting in progressive diabetes, blindness, deafness, and other severe neurological defects. WS has been attributed to mutations in the WFS1 gene, which codes for a protein called wolframin. It appears to be important in the regulation of intracellular $\mathrm{Ca}^{+2}$ homeostasis. ${ }^{7,8}$

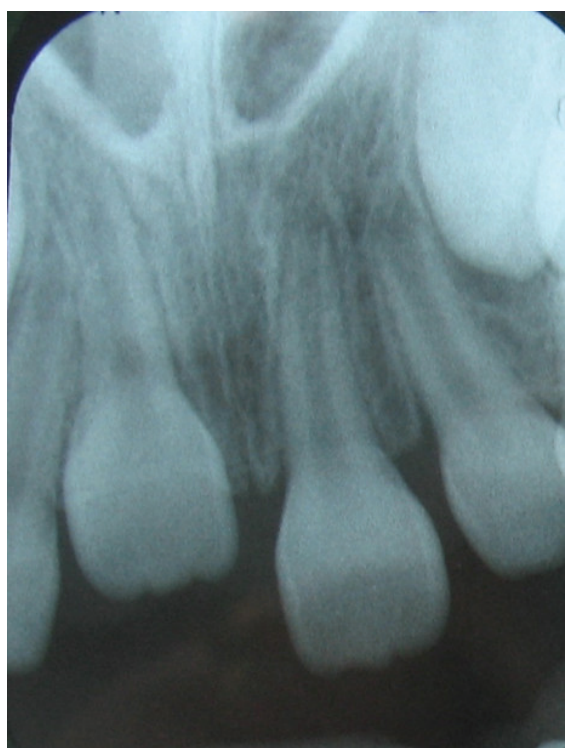

Fig. 4. Initial periapical radiograph revealing complete intrusion of tooth 11

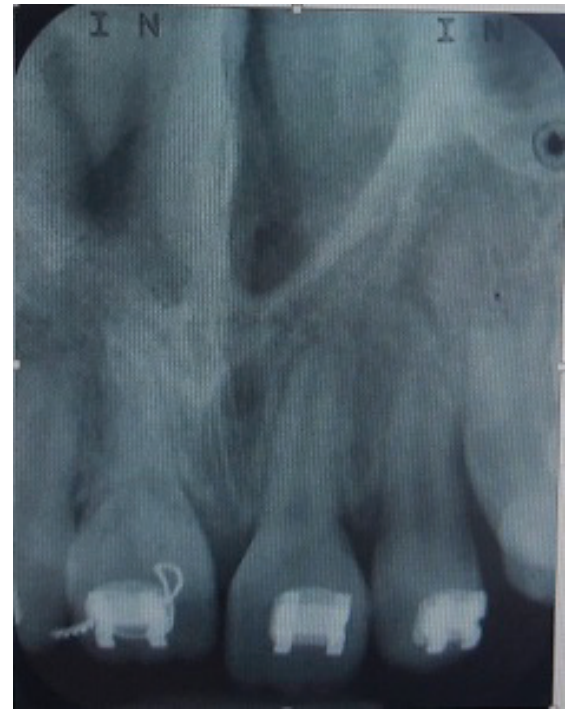

Fig. 5. Radiograph before surgical procedure showing the disappearance of periodontal space around tooth 11

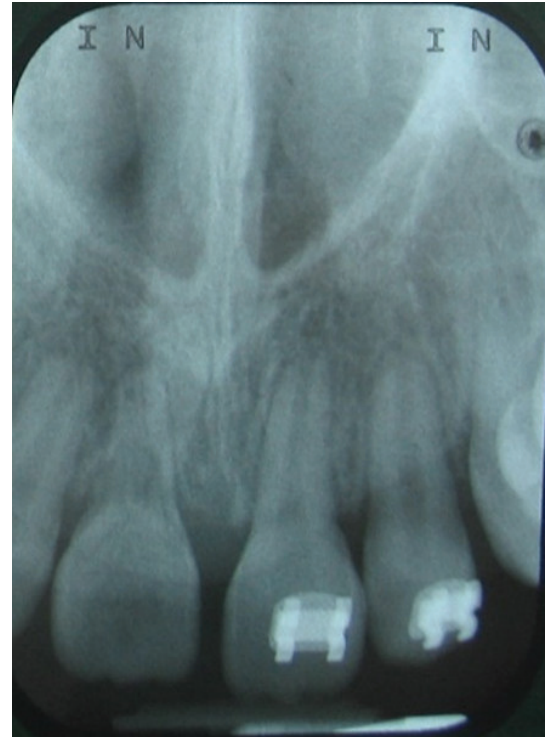

Fig. 6. Periapical radiograph 22 months following trauma showing inflammatory root resorption 
Twenty-two months after the trauma, the right upper incisor was in slight infraocclusion (re-eruption of 7 $\mathrm{mm}$ ) in relation to the homolog. Endodontic treatment was not begun during this time, because the patient failed to report for follow-up visits to the Department of Pedodontics. Also, a pink spot in the cervical area of the maxillary right central incisor appeared, which gave rise to the suspicion of inflammatory resorption. Radiographic examination confirmed the presence of severe inflammatory root resorption and the decision was made to debond the orthodontic appliances and extract the tooth (Fig. 6). The patient was provided with an orthodontic appliance which simultaneously replaced the missing upper right central incisor.

\section{Discussion}

Intrusive luxation in permanent teeth is one of the most severe dental traumas. The main etiological factors include bicycle accidents, sports, recreational activities, or falls., ${ }^{4,5}$ A longitudinal clinical and radiographic evaluation of intruded teeth in a pediatric population, undertaken by Siebra Moreira Neto et al., demonstrated that tooth intrusion was twice as frequent in males and the maxillary central incisors were the most commonly affected teeth (93.3\%), which is related to their anatomic position in the dental arch. ${ }^{10}$ The cases reported here also confirmed these findings. Both our patients were males with traumatically intruded permanent upper right central incisors.

Treatment options for traumatically intruded teeth are still widely discussed in the literature. Although there is a paucity of evidence-based data from randomized control trials to evaluate the most effective treatment for traumatically intruded teeth, according to the International Association of Dental Traumatology (IADT), the stages in root development and intrusion level are the determining factors in choosing the most appropriate treatment methods. ${ }^{11}$ Current management strategies include passive repositioning by waiting for the tooth to regain its preinjury position, and active repositioning, i.e., immediate surgical repositioning or repositioning with traction. ${ }^{12}$ Waiting for spontaneous re-eruption is indicated for immature permanent teeth, because of their high potential for eruption and pulp/periodontal repair. ${ }^{13}$

In the present report, the intruded teeth were immature and revealed complete intrusion (tooth dislodgement $>7 \mathrm{~mm}$ ). In cases such as ours, treatment guidelines recommend orthodontic extrusion if passive re-eruption fails to occur within several weeks after injury, which we applied in both our patients. In case report 1, orthodontic extrusion was initiated 4 weeks after the trauma, while in case report 2 after 8 weeks. The variations in the initiation of orthodontic treatment were determined by differences in the progress of spontaneous re-eruption, which allowed for incisal edge exposure sufficient to apply orthodontic brackets.
In case 1 presentation, orthodontic treatment was completed after 1.5 years, achieving normal positioning for the maxillary right central incisor. The 9-month delay in endodontic therapy provided for continued root development and root dentin apposition. Umesan et al. applied an almost comparable procedure and obtained tooth orthodontic replacement 7 months after injury. ${ }^{9}$ It can be assumed that orthodontic repositioning in the aforementioned report progressed more rapidly than in our case due to an earlier stage of root development. However, the authors did not carry out root canal treatment because the pulp responded to the vitality test, while post-treatment review 1 year later revealed that the entire pulp canal appeared partially obliterated. It has been shown that immature teeth present a better prognosis than do those with complete root formation. ${ }^{3,6,9,14}$

Despite the implementation of an identical procedure in case report 2, eruption under traction proceeded unsatisfactorily and radiological examination revealed ankylosis. Therefore, a corticotomy and luxation were administered as supportive treatment to hasten re-eruption. Corticotomy is a procedure where only the cortical bone is cut, perforated, or mechanically altered in a controlled surgical manner, and thus it is defined as the osteotomy of the cortical bone. In light of some reports, this procedure helps orthodontic tooth movement by accelerated bone metabolism due to controlled surgical damage, so it is called corticotomy-assisted orthodontics. ${ }^{15,16}$ According to Bhattacharya et al., corticotomy techniques reduce the time taken for re-eruption when compared with conventional orthodontic treatment by 30-50\%. ${ }^{16}$ In case 2 presentation, despite decortication and luxation, orthodontic extrusion was unsatisfactory and ankylosis was observed. The incidence of replacement root resorption after intrusions ranges from 25\% to $50 \%$. This occurs more often with incisors that have been severely intruded and those that have been repositioned with traction forces. ${ }^{17}$ Early radiological diagnosis is difficult because initial changes are usually found on the labial or lingual root surface.

Takahashi et al. suggest the use of orthodontic force after luxation to prevent ankylosis, although other authors have noted that in many cases it had not brought positive results. ${ }^{18,19}$ Furthermore, in case 2, we noticed that the intruded tooth exhibited severe inflammatory internal root resorption, which is known to be a frequent complication of extensive tooth intrusion. ${ }^{20}$ This was confirmed in the study by Wigen et al. ${ }^{5}$

The 2 cases described of severe tooth intrusions in patients of a similar age showed varied outcomes. The most likely causes of these differences were: ankylosis; inflammatory root resorption; and the $2^{\text {nd }}$ patient's systemic condition. Besides suffering from type 1 diabetes, the boy developed signs of optical atrophy and was referred for diagnosis with suspected Wolfram syndrome. 


\section{Conclusions}

A number of preinjury and injury factors have a significant effect on treatment outcome. According to this report, prognosis after intrusive luxation appears to depend not only on the severity of the trauma, stage of root development and treatment method, but probably also on the patient's systemic condition.

\section{References}

1. Andreasen JO, Bakland LK, Matras RC, Andreasen FM. Traumatic intrusion of permanent teeth. Part 1. An epidemiological study of 216 intruded permanent teeth. Dent Traumatol. 2006;22:83-89.

2. Albadri S, Zaitoun H, Kinirons MJ. UK National Clinical Guidelines in Paediatric Dentistry: Treatment of traumatically intruded permanent incisor teeth in children. Int J Paediatr Dent. 2010;20(Suppl.1):1-2.

3. Andreasen JO, Bakland LK, Andreasen FM. Traumatic intrusion of permanent teeth. Part 3. A clinical study of the effect of treatment variables such as treatment delay, method of repositioning, type of splint, length of splinting and antibiotics on 140 teeth. Dent Traumatol. 2006;22:99-111.

4. Barbosa Luna AH, Fernandes Moreira RW, De Moraes M. Traumatic intrusion of maxillary permanent incisor into the nasal cavity: Report of a case. Dent Traumatol. 2008;24:244-247.

5. Wigen TI, Agnalt R, Jacobsen I. Intrusive luxation of permanent incisors in Norwegians aged 6-17 years: A retrospective study of treatment and outcome. Dent Traumatol. 2008;24:612-618.

6. Alkhalifa JD, Alazemi AA. Intrusive luxation of permanent teeth a systematic review of factors important for treatment decisionmaking. Dent Traumatol. 2014;30:169-175.

7. Megighian D, Savastano M. Wolfram syndrom. Int J Pediatric Otorhinolaryngol. 2004;68:243-247.

8. Mortazavi H, Shahoon H, Khojasteh A. Acute supporative osteomyelitis of the lower jaw in Wolfram syndrome: Report of case and review of literature. Oral Oncol EXTRA. 2005;41:191-194.

9. Umesan UK, Chua KL, Kok EC. Delayed orthodontic extrusion of a traumatically intruded immature upper permanent incisor - A case report. Dent Traumatol. 2014;30:406-410.

10. Siebra Moreira Neto JJ, Oliveira Gondim J, Matias De Carvalho F, Aparecida Giro EM. Longitudinal clinical and radiographic evaluation of severely intruded permanent incisors in pediatric population. Dent Traumatol. 2009;25:510-514.

11. International Association for Dental Traumatology website. http://www.iadt-dentaltrauma.org/. Accessed January 21, 2011.

12. Kalwitzki M, Weiger R. An intrusion injury as as an example of interdisciplinary aspects in dental traumatology: A case report. Quintessence Int. 2005;36:234-242.

13. Faria G, Silva RAB, Fiori-Junior M, Nelson-Filho P. Re-eruption of traumatically intruded mature permanent incisor: Case report. Dent Traumatol. 2004;20:229-232.

14. Chacko V, Pradhan M. Management of traumatically intruded young permanent tooth with 40-month follow-up. Aust Dent J. 2014;59:240-244.

15. Hassan AH, Al-Fraidi AA, Al Saed SH. Corticotomy assisted orthodontic treatment: review. Open Dent J. 2010;4:159-164.

16. Bhattacharya $\mathrm{P}$, Bhattacharya $\mathrm{H}$, Anjum A, et al. Assessment of corticotomy facilitated tooth movement and changes in alveolar bone thickness - a CT Scan study. J Clin Diagn Res. 2014;8:ZC26-ZC30.

17. Humphrey JM, Kenny DJ, Barret EJ. Clinical outcomes for permanent incisor luxations in pediatric population. I. Intrusions. Dent Traumatol. 2003;19:266-273.

18. Takahashi T, Takogi T, Moryiama K. Orthodontic treatment of a traumatically intruded tooth with ankylosis by traction after surgical luxation. Am J Orthod Dentofacial Orthop. 2005;127:233-241.

19. Turley PK, Crawford LB, Carrington KW. Traumatically intruded teeth. Angle Orthod. 1987;57:234-244.

20. Albadri S, Kinirons MJ, Cole BOI, Welbury RR. Factors affecting resorption in traumatically intruded permanent incisors in children. Dent Traumatol. 2002;18:73-76. 